\title{
Characterization of Magnesium Potassium Phosphate Cement-Based Grouting Material Blended with High Volume Industrial Wastes
}

\author{
Luchen Zhang $\mathbb{D}^{\mathbb{1}},{ }^{1}$ Xuena Jia $\mathbb{D}^{\mathbb{D}},{ }^{1}$ Chao Wang $\mathbb{D}^{2},{ }^{2}$ Quanguo Jiang $\mathbb{D}^{3},{ }^{3}$ and Chaoqun Sun $\mathbb{D}^{1}$ \\ ${ }^{1}$ School of Transportation and Civil Engineering, Shandong Jiaotong University, Jinan 250357, China \\ ${ }^{2}$ Shandong Provincial Communications Planning and Design Institute Group Co.,Ltd., Jinan 250031, China \\ ${ }^{3}$ Shandong Geololgy Topographic Institute, Jinan 250013, China \\ Correspondence should be addressed to Xuena Jia; jiaxuena1023@163.com
}

Received 8 January 2022; Revised 26 January 2022; Accepted 31 January 2022; Published 27 February 2022

Academic Editor: Yonghong Wang

Copyright $(92022$ Luchen Zhang et al. This is an open access article distributed under the Creative Commons Attribution License, which permits unrestricted use, distribution, and reproduction in any medium, provided the original work is properly cited.

In the present research, industrial wastes, e.g., fly ash (FA), lithium slag (LS), ground granulated blast furnace slag (GGBS), and red mud (RM) were utilized to prepare the magnesium phosphate cement (MPC)-based grouting material by a two-component grouting method. Successive additions of GGBS within 40\% (C1-C5) led to reduced fluidity, increased pH value, and shortened setting time. The compressive strength increased first and then decreased. The strength value reached the maximum at a $20 \%$ dosage (C3). Increasing the content of RM from $0 \%$ (C4) to $25 \%$ (C9) resulted in prolonged setting time and an increased $\mathrm{pH}$ value. The fluidity and compressive strength increased first and then decreased. The fluidity and strength value became the highest at a $15 \%$ additive ratio (C7). GGBS can significantly improve the strength and water resistance at 7 days and 28 days by the potential hydraulic property. RM has a smaller particle size than MP, making the microstructure denser by the pore-filling effect. Thus, the drying shrinkage was increased after adding GGBS, while it was decreased when incorporating RM. The MPC-based grouting material has a controllable short setting of 3-21 min, self-leveling fluidity above $200 \mathrm{~mm}$, a near-neutral $\mathrm{pH}$ value, high early strength (1 day compressive strength of $5 \mathrm{MPa}$ ), minor drying shrinkage (one-tenth of OPC), and excellent water resistance (over $85 \%$ ), which is much superior to traditional grouting materials.

\section{Introduction}

Water inrush is one of the geological disasters that frequently happens during the construction of underground engineering [1]. It consumes time, workforce, materials, equipment, and threatens the life safety of construction personnel [2]. According to the statistics, $50 \%$ of underground projects are located in karst areas. Among the disasters involving underground constructions, the water inrush disaster caused by the underground space construction in the karst area ranks first $[3,4]$.

Grouting is an effective means to control the water inrush. It means injecting the prepared grouting material through the matching equipment and using the suitable grouting process to inject the parts that need to be reinforced
[5]. Nowadays, grouting materials adapted to specific engineering needs have become the research hotspot. The existing grouting materials still have various applicability problems [6]. The commonly used cement-based grouting material has an uncontrollable setting time, poor stability, easy layering and segregation, and low strength in the later stages $[7,8]$. Although the water glass solution has the advantages of adjustable setting time, controllable strength, and nontoxicity, it has poor water corrosion resistance, poor durability, and high cost [9]. Organic polymer grouting material has better working performance than cement-based slurry. However, its cost is exceptionally high and it is easy to cause environmental pollution, making it unsuitable for shield tunnel construction $[10,11]$. Therefore, it is extremely important to develop a grouting material that meets engineering requirements, has adjustable setting time, good 
stability, high early strength, excellent water resistance, and green environmental protection $[12,13]$.

Magnesium phosphate cement (MPC), as a kind of chemically bonded phosphate ceramics, has the advantages of fast setting, super early strength, minor shrinkage, good volume stability, and low environmental pollution (the slurry $\mathrm{pH}$ is close to neutral) $[14,15]$. It is widely used in engineering reinforcement $[16,17]$. An MPC has a high initial fluidity (self-leveling) and a quick transformation from a fluid state to a plastic body. Thus, it has been applied as a self-leveling repair material, 3D printing ink, and twocomponent grouting material $[18,19]$.

Nowadays, more and more solid wastes, e.g., red mud (RM), steel slag (SS), lithium slag (LS), fly ash (FA), and ground granulated blast furnace slag (GGBS), are discharged as industrial byproducts, and their disposal and utilization are complex problems $[20,21]$. Industrial waste can be well utilized in MPC. They can reduce the cost, optimize the hydration process, and improve the mechanical properties [22]. Previous researchers have found that the active components in industrial waste residues can react in MPC while the inert components of fine particles can play a porefilling effect [23]. The spherical particles in FA can play a "rolling bearing" effect in the fresh slurry and improve the fluidity [24]. The active aluminum siliceous components in metakaolin can participate in the reaction in MPC to form amorphous aluminum phosphate silica gel and improve the cementitious property of the hardened matrix [25].

Hence, in the present research, industrial wastes (FA, LS, GGBS, and RM) were utilized to prepare the MPC-based grouting material by a two-component grouting method. The effects of GGBS and RM addition were explored by preparing several groups with different mix proportions. Then, the fluidity, $\mathrm{pH}$ value, and setting time of the fresh slurry were analyzed. After hardening, the compressive strength, water resistance, and drying shrinkage of hardened samples were measured. The microscopic tests: X-ray diffraction (XRD), scanning electron microscopy (SEM), and mercury intrusion porosimetry (MIP), were applied to investigate the hydration products and microstructure. The research results enrich the knowledge about large-volume industrial waste-based MPC grouting material, effectively solving the water inrush problem in underground engineering constructions and significantly utilizing industrial solid waste $[3,26]$.

\section{Materials and Methods}

2.1. Raw Materials. The industrial-grade dead burned magnesia powder (MP) was obtained from Haicheng city, Liaoning province. It had a specific surface area of $320 \mathrm{~m}^{2} /$ kg. Ammonium dihydrogen phosphate $\left(\mathrm{NH}_{4} \mathrm{H}_{2} \mathrm{PO}_{4}, \mathrm{APD}\right)$ was provided by the Shifang company in Sichuan province. The grains were 100 mesh and had a purity level higher than $95.0 \%$. Borax was used as the retarder. It was of industrial grade, having a purity level above $97.5 \%$.

Fly ash (FA) was produced by the Xiangtan power plant in Hunan province, and lithium slag (LS) was bought from Jiangli New Material Co., Ltd. in Jiangxi province. The ground granulated blast furnace slag (GGBS) of S95 grade was bought from Shanghai Baosteel Group. The Bayer red mud (RM) fabricated in the alumina extraction in Zhengzhou city, Henan province were used. The specific surface areas of FA, LS, GGBS, and RM were $560 \mathrm{~m}^{2} / \mathrm{kg}$, $245 \mathrm{~m}^{2} / \mathrm{kg}, 430 \mathrm{~m}^{2} / \mathrm{kg}$, and $570 \mathrm{~m}^{2} / \mathrm{kg}$, respectively. The particle size of LM was the largest among these raw materials, and RM was the smallest.

As shown in Figure 1, FA mainly consisted of small spherical-shaped particles, while MP, LS, and GGBS grains were of square shapes. The small RM particles had an irregular shape. The chemical compositions of magnesia powder, FA, LS, GGBS, and RM were presented in Table 1. Magnesia powder had a purity level above $92.0 \%$. FA and LS had a high content of alumina $\left(\mathrm{Al}_{2} \mathrm{O}_{3}\right)$ and silica $\left(\mathrm{SiO}_{2}\right)$. GGBS and RM mainly consisted of $\mathrm{Al}_{2} \mathrm{O}_{3}, \mathrm{SiO}_{2}$, and calcium oxide $(\mathrm{CaO})$.

2.2. Two-Part Grouting Process. Table 2 lists the mix proportions of MPC-based grouting materials containing different additions of industrial wastes. It was prepared by a two-component grouting method in a 1:1 mass ratio [27]. In the current research, ADP can directly react with GGBS and RM. FA and LF had a low content of $\mathrm{CaO}$. They were of low reactivity and hardly reacted with ADP. Thus, as shown in Table 2, part A included MP, GGBS, and RM, while part B contained ADP, FA, and LS. In each group, the water to binder (MP, GGBS, RM, ADP, FA, and LS) mass ratio was fixed at 0.40 . The borax dosage was $10 \%$ of the mass of the alkali components (MP, GGBS, and RM). From C1 to C5, $0 \%, 10 \%, 20 \%, 30 \%$, and $40 \%$ GGBS were used to replace MP, aiming to study the effect of GGBS in MPC-based grouting material. In $\mathrm{C} 4, \mathrm{C} 6, \mathrm{C} 7, \mathrm{C} 8$, and $\mathrm{C} 9$, the addition of RM was changed from $0 \%$ to $25 \%$, aiming to study the effect of RM.

Figure 2 shows the schematic diagram of the two-part grouting method applied in this research. The fabrication process of the MPC-based grouting material was: (1) mixing the preweighed MP, GGBS, RM, and retarder in a mixer for $2 \mathrm{~min}$; (2) adding water and quickly stirring for 2 minforming component $\mathrm{A}$; (3) component $\mathrm{B}$ was prepared by the same procedure as component $\mathrm{A}$; and (4) mixing up the two components together and stirring at a higher speed for $1 \mathrm{~min}$.

The properties, e.g., fluidity, $\mathrm{pH}$ value, and setting time, were tested immediately after mixing. Then, the slurry was poured into the mold and cast. Some samples were cured in air (temperature of $20 \pm 5^{\circ} \mathrm{C}$ and relative humidity of $60 \pm 10 \%$ ) for the compressive strength test, and the others were cured in water (temperature of $20 \pm 5^{\circ} \mathrm{C}$ and relative humidity of $100 \%$ ) to evaluate the water resistance.

2.3. Testing Methods. The fluidity of the MPC-based grouting material was tested according to GB/T 2419-2005. The setting time was measured based on GB/T 1346-2011. MPC has a short hardening stage, and the final setting time is close to the initial setting time. In this research, only the final 


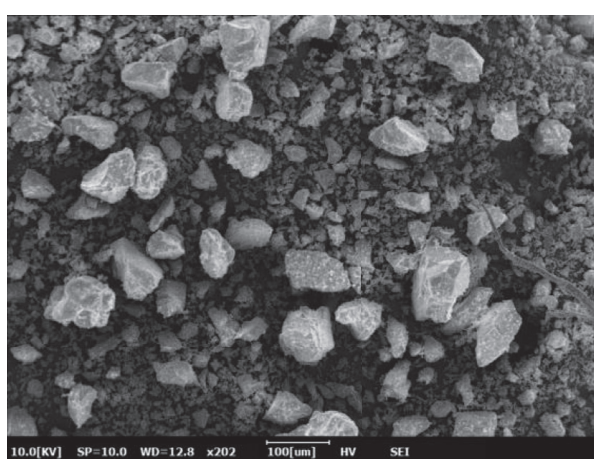

(a)

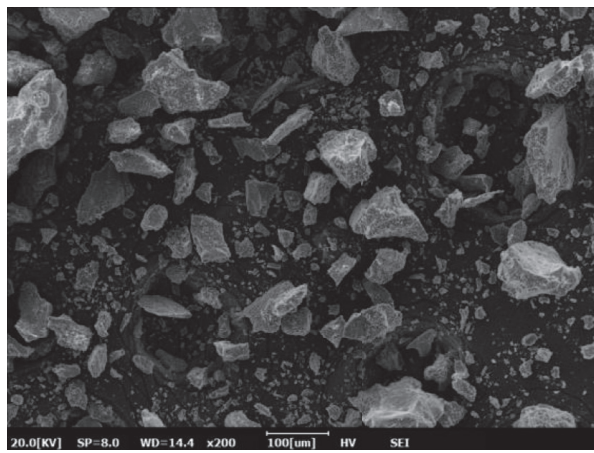

(c)

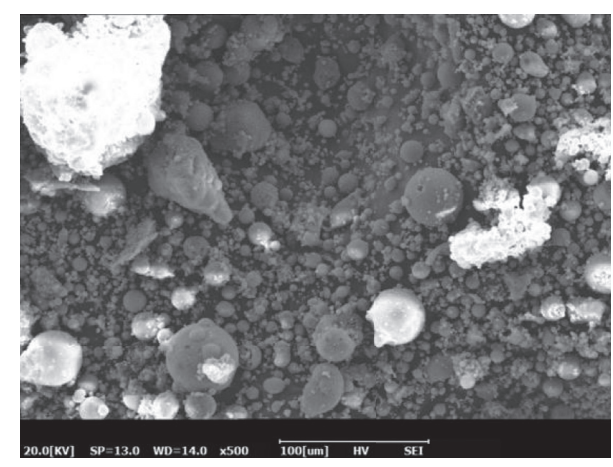

(b)

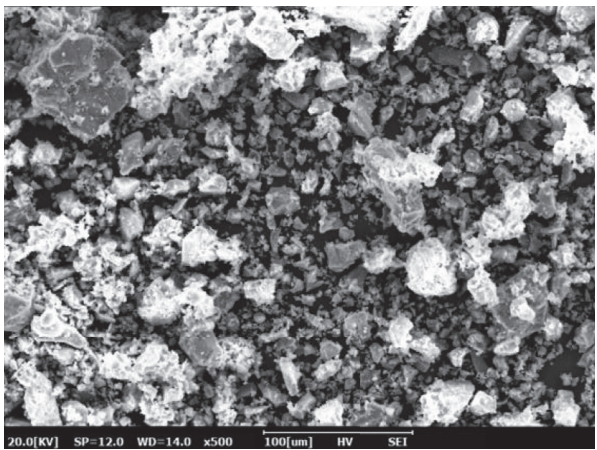

(d)

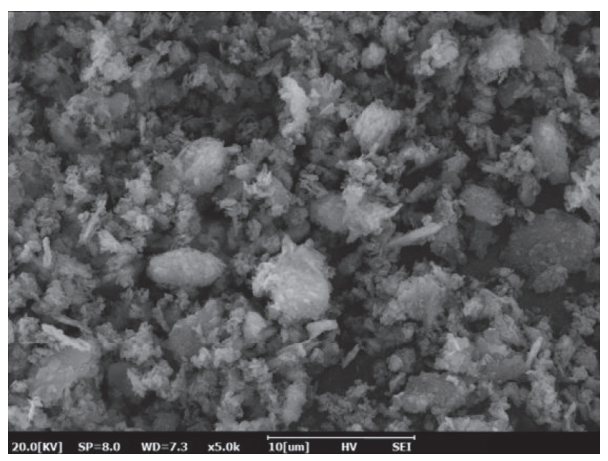

(e)

FIGURE 1: SEM observation of raw materials: (a) MP; (b) FA; (c) LS; (d) GGBS; and (e) RM.

TABLE 1: Chemical compositions of raw materials.

\begin{tabular}{lccccccccc}
\hline \multirow{2}{*}{ Raw material } & \multicolumn{9}{c}{ Chemical composition (\%) } \\
& $\mathrm{MgO}$ & $\mathrm{Al}_{2} \mathrm{O}_{3}$ & $\mathrm{CaO}$ & $\mathrm{Fe}_{2} \mathrm{O}_{3}$ & $\mathrm{~K}_{2} \mathrm{O}$ & $\mathrm{Na}_{2} \mathrm{O}$ & $\mathrm{SiO}_{2}$ & $\mathrm{SO}_{3}$ & $\mathrm{P}_{2} \mathrm{O}_{5}$ \\
\hline MP & 92.03 & 0.51 & 2.81 & 0.34 & 0.01 & 0.01 & 3.65 & 0.01 \\
FA & 1.66 & 26.13 & 6.21 & 6.01 & 1.35 & 0.87 & 53.22 & 1.22 \\
LS & 2.01 & 21.87 & 8.71 & 2.31 & 1.01 & 7.11 & 47.52 & 5.40 & 0.76 \\
GGBS & 5.44 & 13.01 & 43.25 & 0.23 & 0.22 & 0.11 & 34.22 & 1.71 & 0.21 \\
RM & 1.01 & 25.44 & 18.91 & 15.33 & 2.86 & 8.02 & 22.56 & 0.03 \\
\hline
\end{tabular}

setting time was measured. A PHS-3E acidity meter was used to test the $\mathrm{pH}$ value of the fresh slurry, and the instrument had to be calibrated before this measurement.

The compressive strength of the hardened sample was measured according to GB/T 17671-2005. The size of the sample was $40 \mathrm{~mm} \times 40 \mathrm{~mm} \times 160 \mathrm{~mm}$. It had to be split into two sections through the flexural test, and then the compressive strength test was conducted. The photos of the fluidity, $\mathrm{pH}$ value, and compressive strength tests are presented in Figure 3.

The water resistance $\left(W r_{n}\right)$ of the MPC-based grouting material was characterized by comparing the strength of the air-curing and water-curing samples at the same curing age [28]. The calculation formula is 
TABLE 2: Mix proportions of MPC-based grouting materials containing industrial wastes.

\begin{tabular}{|c|c|c|c|c|c|c|c|c|c|c|}
\hline \multirow{2}{*}{ Group } & \multicolumn{5}{|c|}{ Part A } & \multicolumn{5}{|c|}{ Part B } \\
\hline & $m_{\mathrm{MP}}$ & $m_{\mathrm{GGBS}}$ & $m_{\mathrm{RM}}$ & $m_{\text {retarder }}$ & $m_{\text {water }}$ & $m_{\mathrm{ADP}}$ & $m_{\mathrm{FA}}$ & $m_{\mathrm{LS}}$ & $m_{\text {retarder }}$ & $m_{\text {water }}$ \\
\hline $\mathrm{C} 1$ & 3 & 0 & 0 & 0.15 & 1.2 & 1 & 1 & 1 & 0.15 & 1.2 \\
\hline $\mathrm{C} 2$ & 2.7 & 0.3 & 0 & 0.15 & 1.2 & 1 & 1 & 1 & 0.15 & 1.2 \\
\hline $\mathrm{C} 3$ & 2.4 & 0.6 & 0 & 0.15 & 1.2 & 1 & 1 & 1 & 0.15 & 1.2 \\
\hline $\mathrm{C} 4$ & 2.1 & 0.9 & 0 & 0.15 & 1.2 & 1 & 1 & 1 & 0.15 & 1.2 \\
\hline C5 & 1.8 & 1.2 & 0 & 0.15 & 1.2 & 1 & 1 & 1 & 0.15 & 1.2 \\
\hline C6 & 1.8 & 0.9 & 0.3 & 0.15 & 1.2 & 1 & 1 & 1 & 0.15 & 1.2 \\
\hline $\mathrm{C} 7$ & 1.65 & 0.9 & 0.45 & 0.15 & 1.2 & 1 & 1 & 1 & 0.15 & 1.2 \\
\hline $\mathrm{C} 8$ & 1.5 & 0.9 & 0.6 & 0.15 & 1.2 & 1 & 1 & 1 & 0.15 & 1.2 \\
\hline $\mathrm{C} 9$ & 1.35 & 0.9 & 0.75 & 0.15 & 1.2 & 1 & 1 & 1 & 0.15 & 1.2 \\
\hline
\end{tabular}

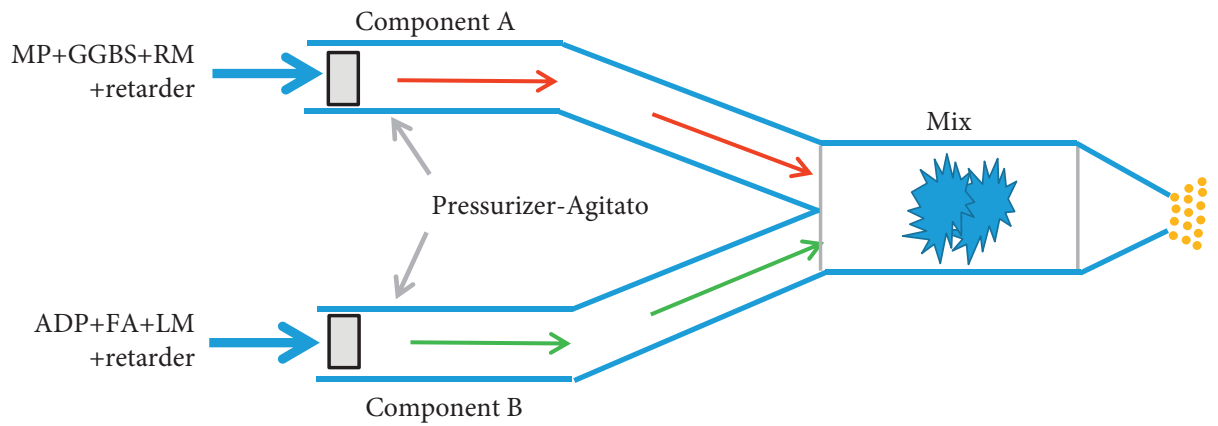

Figure 2: Schematic diagram of two-part grouting method [28].

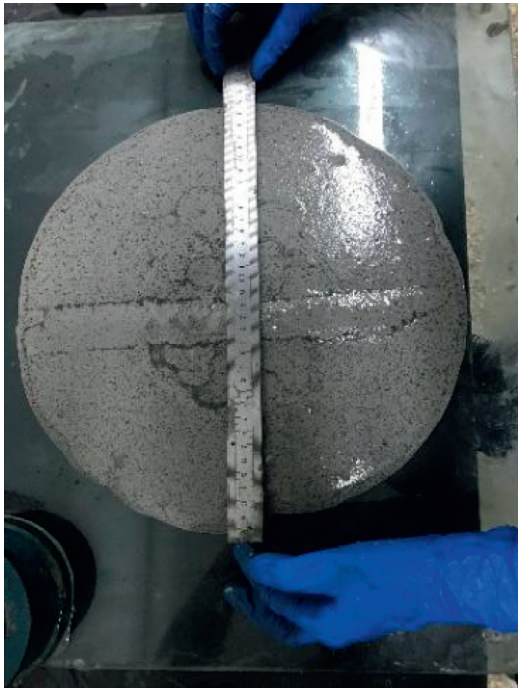

(a)

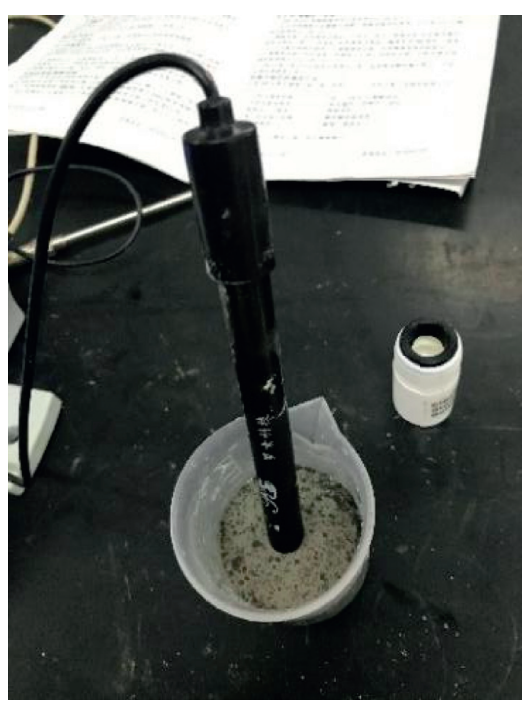

(b)

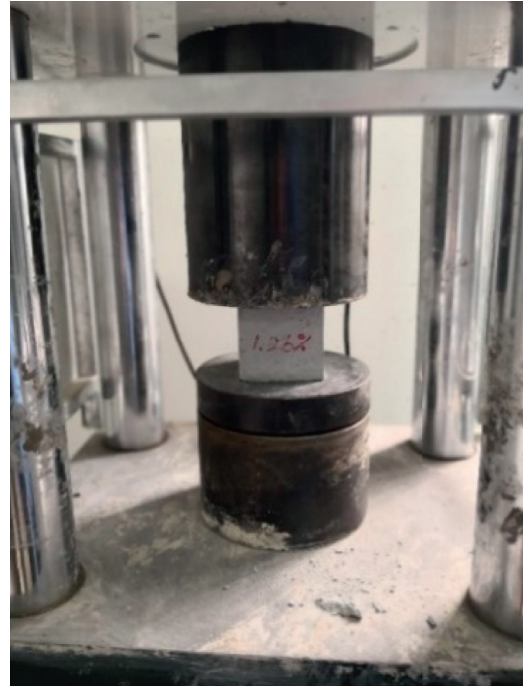

(c)

FIgURE 3: Tests on MPC-based grouting material: (a) fluidity; (b) $\mathrm{pH}$ value; and (c) compressive strength.

$$
W r_{n}=\frac{f_{n}}{F_{n}} \times 100 \% .
$$

In this formula, $W r_{n}$ is the water resistance of the MPC-based grouting material at $n$ days, $f_{n}$ is the compressive strength of the hardened sample cured in water for $n$ days, and $F_{n}$ is the compressive strength of the hardened sample cured in air for $n$ days.
The drying shrinkage of the MPC-based grouting material was tested with reference to JC/T 603-2004. At 3 h, the length of each sample was measured as the initial length $\left(L_{0}\right)$, and the length $\left(L_{t}\right)$ of the sample after curing $1,3,7,14,28$, and 60 days was recorded. The drying shrinkage can be calculated as

$$
\varepsilon_{t}=\frac{L_{t}-L_{0}}{250} \text {. }
$$


In this formula, 250 is the effective length $(\mathrm{mm})$ of the sample.

Before XRD, SEM, and MIP analysis, the collected samples after curing 28 days were terminated the hydration process by immersing in isopropyl alcohol for 7 days. Then, they were dried in a vacuum desiccator. For the XRD test, the dried samples had to be ground into fine powders. A D8ADVANCE (Bruker) X-ray diffractometer machine, with the $\mathrm{Cu}-\mathrm{Ka}$ radiation of $40 \mathrm{~mA} / 40 \mathrm{kV}$, was applied to analyze the hydration product from $5^{\circ}$ to $70^{\circ}$ at a $2^{\circ} / \mathrm{min}$ scanning rate. For the SEM test, the samples had to be gold coated and observed by an SEM machine (Thermo APREO S A5-112). MIP was used to test the porosity and pore structure distribution of samples (particle size of 2-3 mm). An Auto Pore IV 9500 mercury injection machine was used.

\section{Experimental Results}

3.1. Working Performance of Fresh MPC-Based Grouting Material. Table 3 lists the $\mathrm{pH}$ value of the fresh MPC-based grouting material. The $\mathrm{pH}$ value of the fresh slurry increased continuously with the increase of GGBS content, from 6.10 (C1-0\% GGBS) to 8.11 (C5-40\% GGBS). As shown in Table 1, GGBS contains a higher percentage of $\mathrm{CaO}$ than MP. $\mathrm{CaO}$ has higher alkalinity and reactivity than $\mathrm{MgO}$, leading to an increased $\mathrm{pH}$ value [29]. Based on $\mathrm{C} 4$, when increasing the dosage of $\mathrm{RM}$ from $0 \%$ to $25 \%$, the $\mathrm{pH}$ value of the fresh slurry slightly changed from 7.61 (C4-0\% RM) to 7.98 (C9$25 \% \mathrm{RM}$ ). In Table 1, RM contains $18.91 \% \mathrm{CaO}, 8.02 \%$ $\mathrm{Na}_{2} \mathrm{O}$, and $2.86 \% \mathrm{~K}_{2} \mathrm{O}$. It is more alkaline than MP but still lower than GGBS. Thus, adding GGBS leads to a higher $\mathrm{pH}$ value increase rate than incorporating RM.

Figure 4 presents the fluidity and setting time of the fresh MPC-based grouting material with different additions of GGBS. Successive additions of GGBS led to a continuously decreased fluidity and reduced setting time. In $\mathrm{C} 1(0 \%$ GGBS), the fluidity and setting time were $245 \mathrm{~mm}$ and $21 \mathrm{~min}$, respectively. They changed to $208 \mathrm{~mm}$ and $3 \mathrm{~min}$, significantly, after adding 40\% GGBS (C5). Because the reactivity of GGBS is higher than MP, the incorporation of GGBS can promote the early hydration rate in MPC-based grouting material, resulting in a shortened setting time and decreased fluidity [30,31].

Among these groups, $\mathrm{C} 4$ had a fluidity of $220 \mathrm{~mm}$ and a setting time of $5 \mathrm{~min}$, which was suitable for application in the construction field. Based on C4, another industrial waste RM was tried to be utilized in MPC-based grouting material. Figure 5 displays the fluidity and setting time of the fresh MPC-based grouting material with different RM additions. The fluidity of the slurry first increased from $220 \mathrm{~mm}$ (C4$0 \% \mathrm{RM})$ to $231 \mathrm{~mm}(\mathrm{C} 7-15 \% \mathrm{RM})$, and further additions of $\mathrm{RM}$ resulted in a slightly decreased fluidity. Considering that the particle distribution of RM is different from that of MP, adding an appropriate amount of RM can improve the particle gradation of raw materials and increase fluidity [32]. When RM was excessive, the fluidity was further reduced. As shown in Figure 5, successive additions of RM led to a slightly prolonged setting time. In C4 (0\% RM), the setting time was $5 \mathrm{~min}$. It increased to $10 \mathrm{~min}$ after adding $25 \% \mathrm{RM}$
TABLE 3: The pH value of the fresh MPC-based grouting material.

\begin{tabular}{lccccccccc}
\hline Group & $\mathrm{C} 1$ & $\mathrm{C} 2$ & $\mathrm{C} 3$ & $\mathrm{C} 4$ & $\mathrm{C} 5$ & $\mathrm{C} 6$ & $\mathrm{C} 7$ & $\mathrm{C} 8$ & $\mathrm{C} 9$ \\
\hline $\mathrm{pH}$ value & 6.10 & 6.52 & 7.04 & 7.61 & 8.11 & 7.73 & 7.85 & 7.91 & 7.98 \\
\hline
\end{tabular}

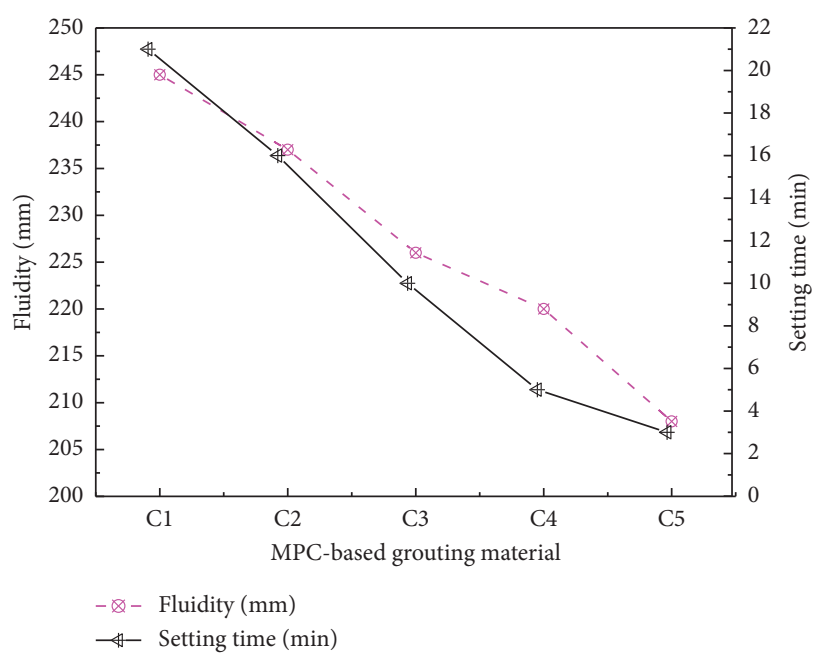

Figure 4: The fluidity and setting time of the fresh MPC-based grouting material with different additions of GGBS.

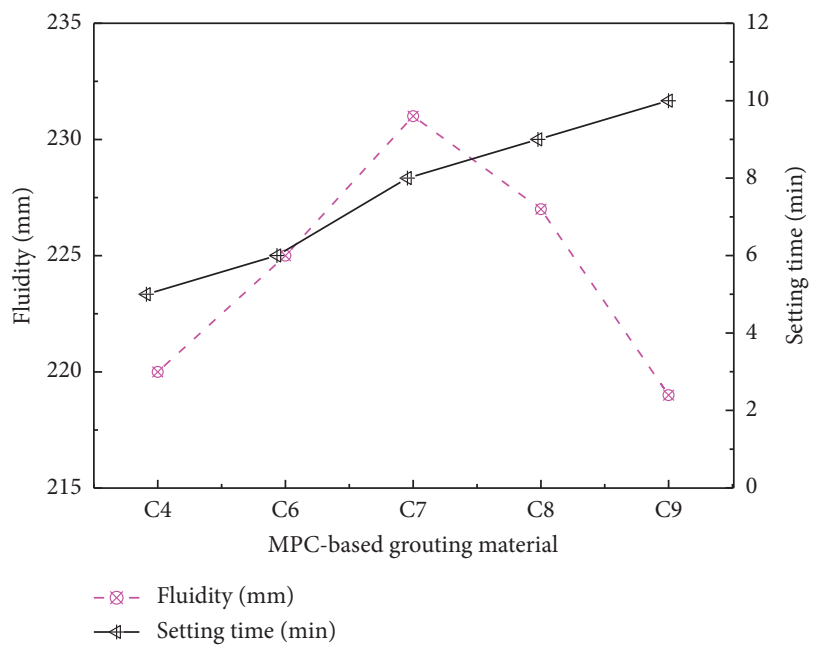

FIgURE 5: The fluidity and setting time of the fresh MPC-based grouting material with different additions of RM.

(C9). Because the reactivity of RM is lower than that of MP, the incorporation of RM could decrease the early hydration rate in MPC-based grouting material, resulting in a prolonged setting time [33]. All these groups had fluidity higher than $180 \mathrm{~mm}$, reaching the level of self-leveling.

Compared with the traditional cement and water glass grouting materials $(\mathrm{pH}$ value $>12.0)$, the $\mathrm{pH}$ value of the MPC-based grouting material applied in the current experiment is close to neutral $[32,33]$. The novel MPC grouts containing a large volume of GGBS and RM are eco-friendly and high-performance. Besides, the MPC-based grouting material can achieve an adjustable setting time from $3 \mathrm{~min}$ to $21 \mathrm{~min}$, which meets the engineering need. 
3.2. Mechanical Property of Hardened MPC-Based Grouting Material. Figure 6 presents the effects of GGBS content on the compressive strength of MPC-based grouting material. GGBS has a significant impact on compressive strength. At 1st day, the compressive strengths from $\mathrm{C} 1$ (0\% GGBS) to C5 (40\% GGBS) were 6.5 MPa, 5.4 MPa, 4.6 MPa, 4.0 MPa, and $3.5 \mathrm{MPa}$, respectively. The early strength (1 day) was continuously reduced with the successive addition of GGBS. When cured from 1 day to 7 days, the strength growth rate of the group containing GGBS was higher than the basic group $\mathrm{C} 1$. The compressive strengths of the five groups at 7 days were 10.2 $\mathrm{MPa}, 10.5 \mathrm{MPa}, 11.2 \mathrm{MPa}$, 11.0 MPa, and 10.5 $\mathrm{MPa}$, respectively, in which C3 $(20 \%$ GGBS) had the highest strength value. After curing for 28 days, the compressive strength of $\mathrm{C} 3$ increased to 15.7 $\mathrm{MPa}$, which was still the highest among the five groups.

The incorporation of GGBS significantly shortens the setting time, and the fresh slurry will harden quickly, resulting in insufficient crystal growth, uneven distribution of hydration product, more internal pores, and a decreased early strength [34]. GGBS has a potential hydraulic property [35]. When incorporated into MPC-based grouting material, it can react quickly with phosphate and be activated in the intense exothermic environment during hardening, which enhances the later stage compressive strength [36]. The results in Figure 6 indicate that a proper amount of GGBS will enhance the mechanical property of the grouting material, and when its content exceeds $20 \%$, the mechanical property will also decrease.

Figure 7 presents the effects of RM content on the compressive strength of MPC-based grouting material. RM has a noticeable influence on compressive strength. The strength value increased when the RM content increased from $0 \%(\mathrm{C} 4)$ to $15 \%(\mathrm{C} 7)$. As the RM content increased from $15 \%(\mathrm{C} 7)$ to $25 \%(\mathrm{C} 9)$, the strength value gradually decreased. At 28 days, the strength values of C4, C6, C7, C8, and $\mathrm{C} 9$ were $15.4 \mathrm{MPa}, 16.0 \mathrm{MPa}, 16.8 \mathrm{MPa}, 16.1 \mathrm{MPa}$, and 15.3 MPa, respectively. A suitable amount of RM within $15 \%$ increases the compressive strength of the hardened sample. $\mathrm{RM}$ has finer particles than MP. Adding the proper amount of RM can make the microstructure denser [37, 38]. When $\mathrm{RM}$ is excessive, it will reduce the main hydration product formed in the hardened matrix, which weakens the overall gelation. Thus, the compressive strength decreases.

\subsection{Durability of Hardened MPC-Based Grouting Material.} Figure 8 displays the effects of GGBS content on the drying shrinkage of the MPC-based grouting material. Within the initial 14 days, the drying shrinkage increased rapidly, and the value at 14 days reached about $70 \%$ of that at 60 days. Generally, the dry shrinkage of OPC-based materials can reach 1000 microstrains in 60 days [39]. The dry shrinkage of MPC-based grouting material was only about 50 microstrains at 60 days, which is only one-tenth of OPC. It is the biggest advantage that MPC-based materials have when they are used in engineering repairs. Actually, MPC is formed by the ionic bonds between the metal cations and phosphate

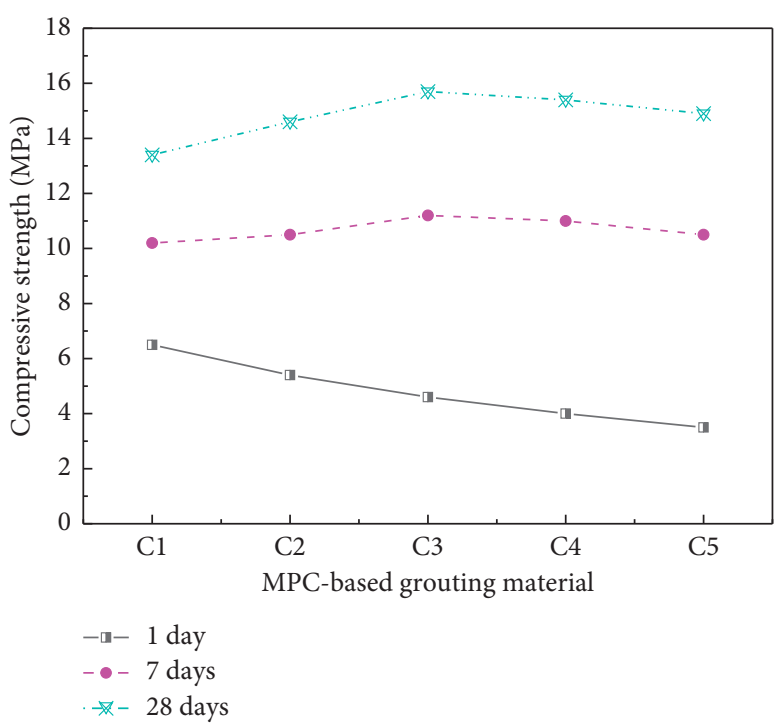

FIGURE 6: The compressive strength of the hardened sample with different additions of GGBS.

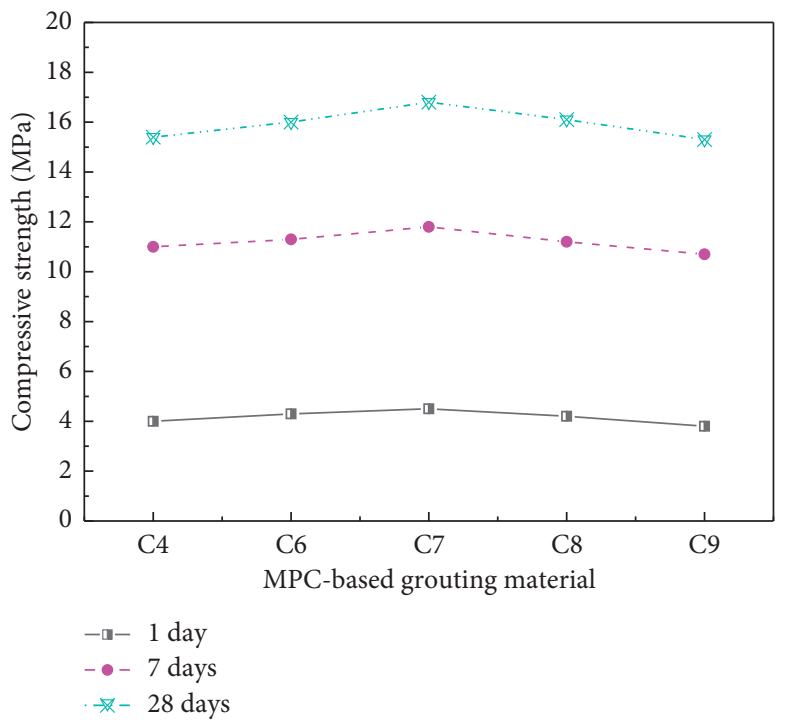

FIGURE 7: The compressive strength of the hardened sample with different additions of RM.

anions, while OPC is bonded by van der Waals forces. Because ionic bonds are stronger than van der Waals forces, MPC has better volume stability than OPC. As shown in Figure 8, the drying shrinkage of $\mathrm{C} 1, \mathrm{C} 2, \mathrm{C} 3, \mathrm{C} 4$, and $\mathrm{C} 5$ at 60 days was 51.2 microstrains, 55.1 microstrains, 58.2 microstrains, 60.3 microstrains, and 64.1 microstrains, respectively. Adding GGBS increased the drying shrinkage of the MPC-based grouting material. GGBS has a strong chemical reactivity in MPC, which improves the hydration degree in the MPC system and increases the shrinkage value $[40,41]$.

Figure 9 displays the effects of RM content on the drying shrinkage of the MPC-based grouting material. The drying shrinkage of C4, C6, C7, C8, and C9 at 60 days was 60.3 microstrains, 58.1 microstrains, 57.2 microstrains, 56.3 


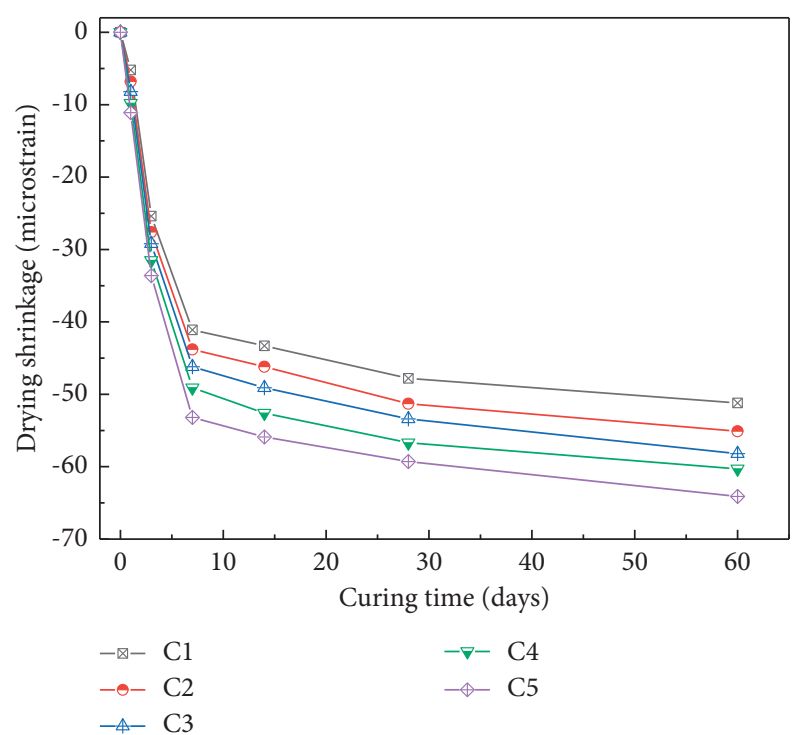

FIGURE 8: The drying shrinkage of the hardened sample with different additions of GGBS.

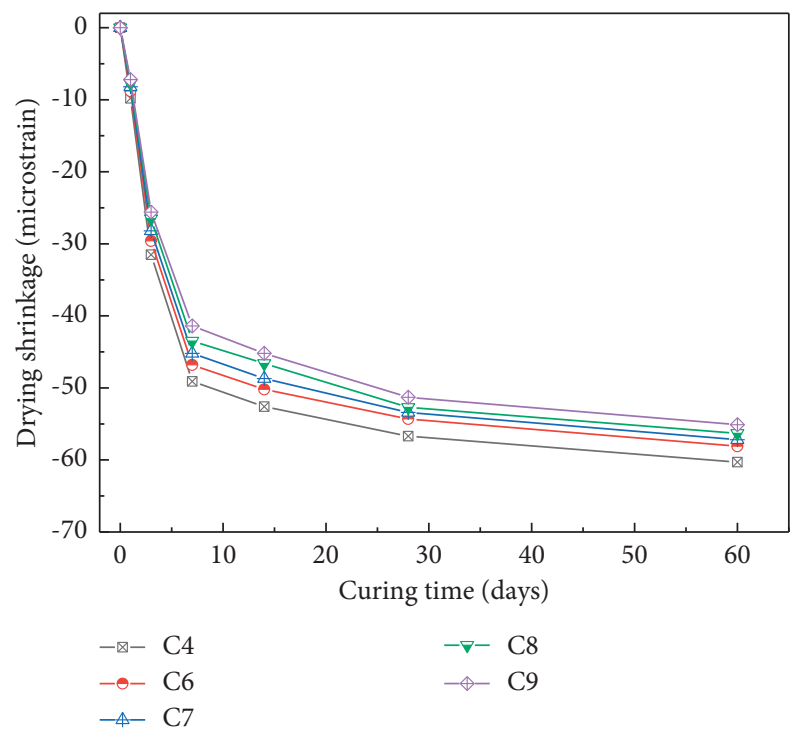

FIGURE 9: The drying shrinkage of the hardened sample with different additions of RM.

microstrains, and 55.1 microstrains, respectively. Adding RM reduces the drying shrinkage of the MPC sample slightly. It is believed that the hydration degree of MPC is the main factor affecting the value of drying shrinkage [42, 43]. Adding RM makes the microstructure of the MPC-based grouting material denser, which will reduce the drying shrinkage.

Different from OPC, MPC has the disadvantage of poor water resistance. Long-term immersion of MPC in water will cause dissolution of reaction products, resulting in increased pores, loose structure, and decreased strength of the hardened paste $[44,45]$. Table 4 lists the water resistance $\left(W r_{n}\right)$ of the hardened MPC-based grouting material. Compared with the sample mixed with GGBS, the basic group-C1 had a higher $W r_{n}$ value at 7 days $(96.1 \%)$. Due to the shortened setting time of the sample containing GGBS, the internal microstructure is loose at an early age and the crystal has not grown well $[30,46]$. Therefore, when immersed in water, the water resistance is poor. GGBS has a potential hydraulic property and can react continuously to enhance the bonding performance in the MPC matrix, leading to increased strength. During the period from 7 days to 28 days, the water resistance of the samples mixed with GGBS significantly improved. The group containing 20\% GGBS (C3) increased from $71.4 \%$ to $86.8 \%$. However, after 28 days of soaking, the basic group (C1) had the lowest $W r_{n}$ value among these groups, which was only $63.2 \%$. It can be seen that the water resistance of the MPC-based grouting material without modified materials is obviously insufficient, and GGBS can significantly enhance the water stability.

Based on C4, the effect of RM on the water resistance of MPC-based grouting material was investigated. As presented in Table 4 , the $W r_{n}$ value of C4 (0\% RM) was $66.3 \%$ and $91.2 \%$ after immersion in water for 7 days and 28 days. When $20 \% \mathrm{RM}$ (C8) was blended, the $W r_{n}$ values at 7 and 28 days were $73.2 \%$ and $93.5 \%$, respectively. It exhibits better water resistance than $\mathrm{C} 4$ at 7 days and 28 days. Adding metakaolin or alumina into MPC can form some aluminosilicate phases, helping to improve the water resistance $[47,48]$. Compared with alumina, RM has a better effect on the long-term water resistance, which is attributed to the newly formed $\mathrm{Mg}-\mathrm{Al}-\mathrm{Fe}$ phosphate gels [31]. Besides, the particle size of RM is finer than that of MP. It can fill the microcracks in the hardened sample and make the microstructure denser [28]. The $W r_{n}$ values from group C3 to C9 were above $85.0 \%$, which reflects good water resistance and meets the engineering requirements.

\section{Mechanism Discussion}

4.1. Hydration Product Analysis. Figure 10 presents the XRD patterns of $\mathrm{C} 1, \mathrm{C} 4$, and $\mathrm{C} 7$ after curing for 28 days. The samples mixed with GGBS and RM did not appear with new characteristic peaks. All three groups can only detect the diffraction peaks of $\mathrm{MgO}$ and struvite $\left(\mathrm{MgNH}_{4} \mathrm{PO}_{4} \cdot 6 \mathrm{H}_{2} \mathrm{O}\right)$ [49]. As shown in these three patterns, the peak intensity of struvite did not change significantly, indicating that the incorporation of GGBS and RM did not hinder the formation of struvite. It is consistent with the compressive strength results. Apart from these crystal phases, MPC contained more than half of the amorphous intermediate product [31]. The hydration products formed by GGBS and RM might be of the amorphous phase, which cannot be detected by XRD.

4.2. Microstructure Evolution. Figure 11 displays the MIP results of hardened MPC-based grouting material after curing for 28 days. As shown in the figure, the total porosity of $\mathrm{C} 1, \mathrm{C} 2, \mathrm{C} 4$, and $\mathrm{C} 7$ was $15.52 \%, 15.41 \%, 15.11 \%$, and $13.99 \%$, respectively.

The porosity of the sample added with $0 \%, 10 \%$, and $30 \%$ GGBS was $15.52 \%, 15.41 \%$, and $15.11 \%$, respectively. As shown in Figure 1, GGBS had a smaller particle size than MP. Adding a suitable amount of fine GGBS 
TABLE 4: The water resistance of the hardened sample.

\begin{tabular}{lccccccccc}
\hline Group & C1 $(\%)$ & C2 (\%) & C3 (\%) & C4 (\%) & C5 (\%) & C6 (\%) & C7 (\%) & C8 (\%) & C9 (\%) \\
\hline 7 days & 96.1 & 78.1 & 71.4 & 66.3 & 65.4 & 69.3 & 71.5 & 73.2 & 72.5 \\
28 days & 63.2 & 83.4 & 86.8 & 91.2 & 90.0 & 92.1 & 92.8 & 93.5 & 91.8 \\
\hline
\end{tabular}

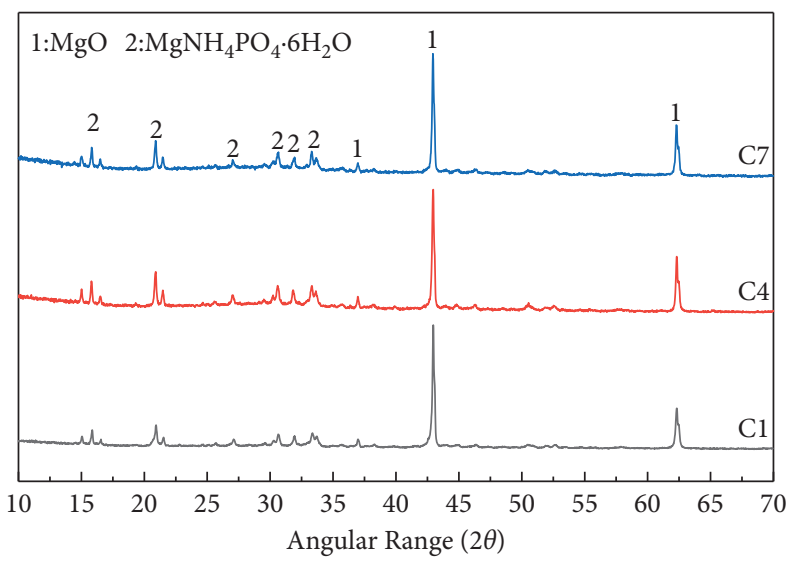

FIgURE 10: XRD patterns of C1, C4, and C7 at 28 days.

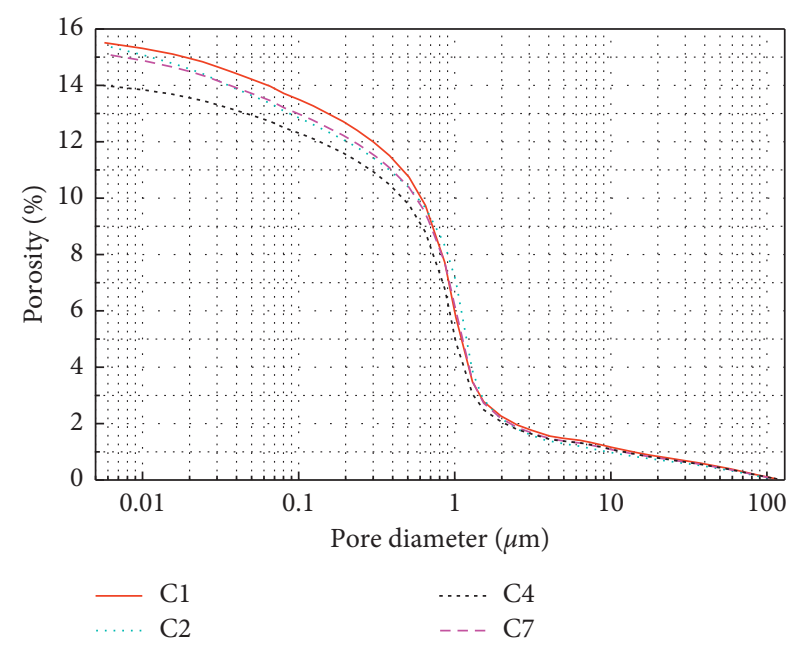

FIGURE 11: MIP results of hardened MPC-based grouting material after curing for 28 days.

particles modified the microstructure of MPC-based grouting material by its chemical effect, leading to increased strength [50]. The calcium oxide contained in GGBS had a higher reactivity than MP in the MPC system. It had a faster reaction rate with $\mathrm{ADP}$ than magnesia. Besides, GGBS has potential hydraulic properties and can itself undergo hydration reactions in MPC. Hence, the porosity of MPC-based material was continuously reduced with successive additions of GGBS [20].

After adding $15 \% \mathrm{RM}$, the total porosity was decreased from $15.11 \%$ to $13.99 \%$. Although the reactivity of RM was lower than that of GGBS, RM had a much smaller particle size than MP and GGBS [51]. A suitable amount of RM can improve the particle distribution of raw powder grains and compact the microstructure. This makes the microstructure denser by the pore-filling effect.

The main mechanism of GGBS and RM in improving the mechanical properties of MPC-based material was different. GGBS led to the formation of more hydrates, while RM had a more significant pore-filling effect. In cement-based materials, the drying shrinkage is inversely proportional to the total amount of hydration products [52]. As shown in the current research, adding GGBS increased the drying shrinkage, while the MPC-based grouting material incorporated with RM had a lower drying shrinkage. The MIP results were consistent with the above analysis.

Figure 12 displays the SEM images of $\mathrm{C} 1, \mathrm{C} 2, \mathrm{C} 4$, and C7 after curing for $28 \mathrm{~d}$. In the basic group $\mathrm{C} 1$, large lumps of particles were observed. They were the residual MgO crystals. Around these particles, struvite crystals in hexagonal shapes were observed. After adding GGBS, the amount of $\mathrm{MgO}$ particles decreased. Many small lumpy grains were distributed on the surface of struvite, which was the phase formed by the reaction of GGBS and ADP [53]. Compared with C1, C2 and C4 had denser microstructures. Because GGBS can hydrate and react with $\mathrm{ADP}$, the amorphous hydration product has a large surface area and has strong gelling properties that tightly bond the internal particles of MPC to form a denser microstructure. As shown in Figure 12(d), the number of small particles increased after adding FM, which were the RM grains [54]. These particles were tightly embedded in the MPC-based grouting material. The hydrates were grown between $\mathrm{MgO}$ crystals and $\mathrm{RM}$ particles, which were distributed widely in the microstructure. Adding a suitable amount of RM can improve the compressive strength by promoting the hydration rate in MPCbased material [31]. The incorporation of 15\% RM improved the particle size distribution of the grains. Besides, the alkali component RM reacted with $\mathrm{ADP}$, which promoted the hydration degree and increased the property of the cement matrix. 


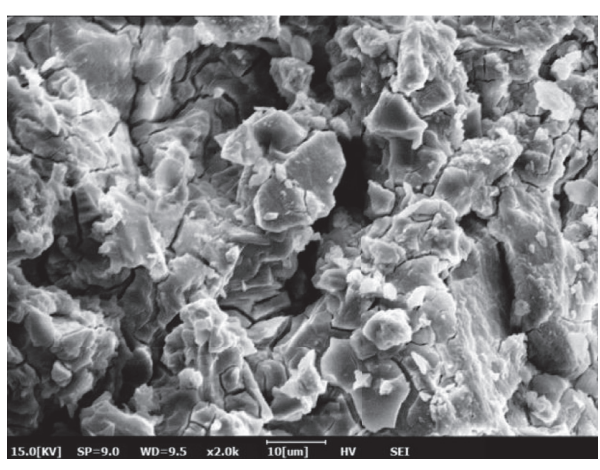

(a)

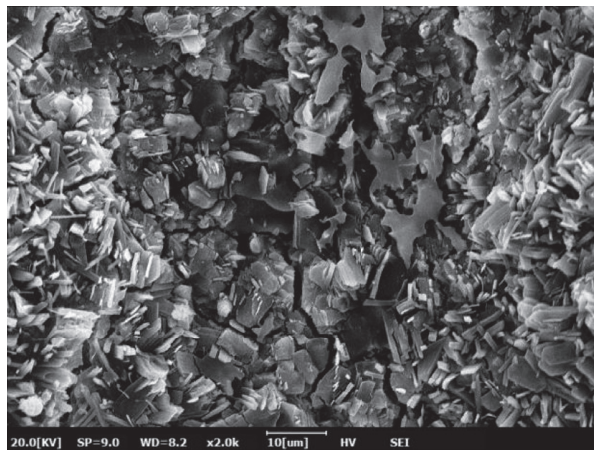

(c)

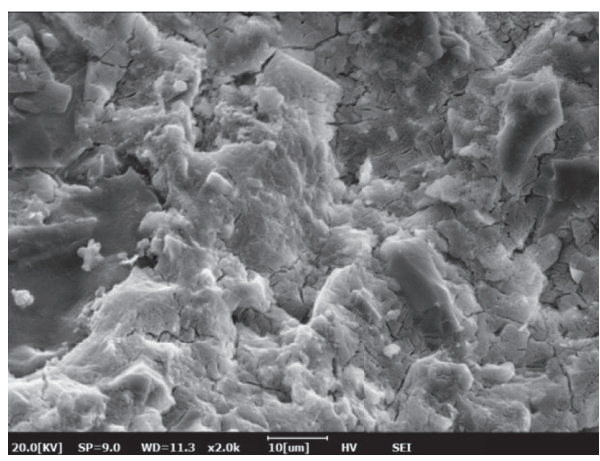

(b)

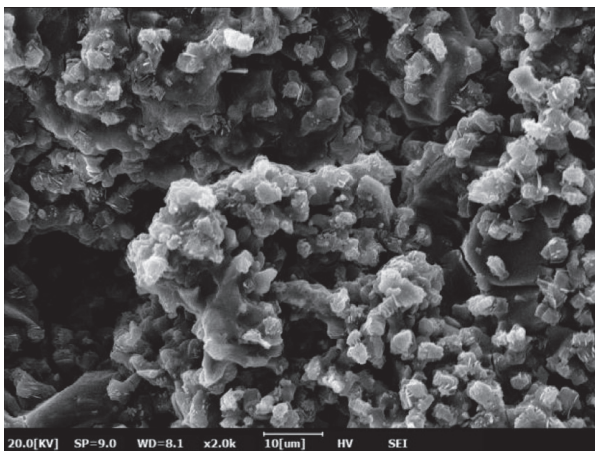

(d)

FIGURE 12: SEM images of hardened MPC-based grouting material after curing for 28 days: (a) C1; (b) C2; (c) C4; and (d) C7.

As shown in Figure 12(d), more gel phases of small-square shape were formed in the sample containing 15\% RM (C7). Although RM has a lower reactivity than GGBS, the compressive strength of the hardened sample containing RM increased from the initial $1 \mathrm{~d}$. It is the synergistic promotion effect between RM and GGBS, resulting in better mechanical properties.

\section{Conclusion}

(1) Successive additions of GGBS within 50\% (C1-C5) led to reduced fluidity, increased $\mathrm{pH}$ value, and shortened setting time. The compressive strength increased first and then decreased, reaching the maximum when the dosage is $20 \%$ (C3). In C3, the fluidity, setting time, $\mathrm{pH}$ value, and 28 days compressive strength were $226 \mathrm{~mm}$, $10 \mathrm{~min}, 7.04$, and $15.6 \mathrm{MPa}$, respectively.

(2) Increasing the dosage of RM from $0 \%$ (C4) to $25 \%$ (C9) resulted in a prolonged setting time and increased $\mathrm{pH}$ value. The fluidity and compressive strength increased first and then decreased. The fluidity and strength value reached the maximum at a $15 \%$ dosage $(\mathrm{C} 7)$. For $\mathrm{C} 7$, the fluidity, setting time, $\mathrm{pH}$ value, and 28 days compressive strength were $231 \mathrm{~mm}, 8 \mathrm{~min}, 7.85$, and $16.8 \mathrm{MPa}$, respectively.

(3) GGBS can significantly improve the later stage strength (7 days, 28 days) and water resistance by the potential hydraulic property. It can react and improve the bonding performance in the matrix. RM has a smaller particle size than MP, making the microstructure denser by the pore-filling effect. Thus, the drying shrinkage is increased after adding GGBS, while it is decreased by adding RM.

(4) The MPC-based grouting material has a controllable short setting of 3-21 min, self-leveling fluidity above $200 \mathrm{~mm}$, a near-neutral $\mathrm{pH}$ value, high early strength (1 day compressive strength of $5 \mathrm{MPa}$ ), minor drying shrinkage (one-tenth of OPC), and excellent water resistance (over $85 \%$ ), which is much superior to traditional grouting materials.

Characterizing MPC-based grouting materials blended with high volume industrial wastes is important to the practical engineering of such materials. However, the present studies are not directly related to real engineering, and there are various other issues that need to be analyzed, e.g., the design of high-efficiency two-component grouting machine, the construction technology, and more investigations need to be carried out to verify the suitability of MAPC for field construction.

\section{Data Availability}

The data used to support the findings of this study are plotted within the article, and the raw data files are available by contacting the corresponding author.

\section{Conflicts of Interest}

The authors declare that there are no conflicts of interest. 


\section{Acknowledgments}

This research was supported by the Doctoral Research Startup Fund of Shandong Jiaotong University (Grant no. 50004930).

\section{References}

[1] S. Li, X. Wang, Z. Xu, D. Mao, and D. Pan, "Numerical investigation of hydraulic tomography for mapping karst conduits and its connectivity," Engineering Geology, vol. 281, p. 105967, 2021 Feb. 2021.

[2] L. Han, L. Wang, X. Ding, H. Wen, X. Yuan, and W. Zhang, "Similarity quantification of soil parametric data and sites using confidence ellipses," Geoscience Frontiers, vol. 13, no. 1, p. 101280, 2022.

[3] J. Cai, J. Pei, Q. Luo, J. Zhang, R. Li, and X. Chen, "Comprehensive service properties evaluation of composite grouting materials with high-performance cement paste for semi-flexible pavement," Construction and Building Materials, vol. 153, pp. 544-556, Oct. 2017.

[4] Z. Dou, S. Tang, X. Zhang et al., "Influence of shear displacement on fluid flow and solute transport in a 3D rough fracture," Lithosphere, vol. 2021, no. Special 4, p. 1569736, 2021.

[5] B. Yuan, Z. Li, Z. Zhao, H. Ni, Z. Su, and Z. Li, "Experimental study of displacement field of layered soils surrounding laterally loaded pile based on transparent soil," Journal of Soils and Sediments, vol. 21, no. 9, pp. 3072-3083, 2021, Sep. 2021.

[6] C. Zhu, K. Zhang, H. Cai et al., "Combined application of optical fibers and CRLD bolts to monitor deformation of a pitin-pit foundation," Advances in Civil Engineering, vol. 2019, pp. 1-16, 2019.

[7] M. Cao, C. Wang, R. Xia et al., "Preparation and performance of the modified high-strength/high-modulus polyvinyl alcohol fiber/polyurethane grouting materials," Construction and Building Materials, vol. 168, pp. 482-489, 2018, Apr. 2018.

[8] M. Gao, J. Xie, Y. Gao et al., "Mechanical behavior of coal under different mining rates: a case study from laboratory experiments to field testing," International Journal of Mining Science and Technology, vol. 31, no. 5, pp. 825-841, 2021, Sep. 2021.

[9] X. Chen, R. Bi, and L. Zhang, "Effect of water-to-cement ratio on sulfo-aluminate type cementitious grouting materials," Magazine of Concrete Research, vol. 71, no. 6, pp. 298-308, 2019, Mar. 2019.

[10] F. Liu, M. Zheng, and Y. Ye, "Formulation and properties of a newly developed powder geopolymer grouting material," Construction and Building Materials, vol. 258, p. 120304, 2020.

[11] C. Cao, W. Zhang, J. Chen, B. Shan, S. Song, and J. Zhan, "Quantitative estimation of debris flow source materials by integrating multi-source data: a case study," Engineering Geology, vol. 291, p. 106222, 2021 Sep. 2021.

[12] C. Ma, G. Chen, Z. Jiang et al., "Rheological properties of magnesium phosphate cement with different $\mathrm{M} / \mathrm{P}$ ratios," Construction and Building Materials, vol. 282, p. 122657, 2021.

[13] Q. Chen, R. Ma, H. Li, Z. Jiang, H. Zhu, and Z. Yan, "Effect of chloride attack on the bonded concrete system repaired by UHPC," Construction and Building Materials, vol. 272, p. 121971, 2021 Feb. 2021.

[14] J. Qin, J. Qian, X. Dai, C. You, H. Ma, and Z. Li, "Effect of water content on microstructure and properties of magnesium potassium phosphate cement pastes with different magnesia-to-phosphate ratios," Journal of the American Ceramic Society, vol. 104, no. 6, pp. 2799-2819, 2021, Jun. 2021.

[15] C. Ma, F. Wang, H. Zhou, Z. Jiang, W. Ren, and Y. Du, "Effect of early-hydration behavior on rheological properties of borax-admixed magnesium phosphate cement," Construction and Building Materials, vol. 283, p. 122701, 2021.

[16] B. Chen, S. Y. Oderji, S. Chandan, and S. Fan, "Feasibility of Magnesium Phosphate Cement (MPC) as a repair material for ballastless track slab," Construction and Building Materials, vol. 154, pp. 270-274, 2017, Nov. 2017.

[17] D. Chen, H. Chen, W. Zhang, J. Lou, and B. Shan, “An analytical solution of equivalent elastic modulus considering confining stress and its variables sensitivity analysis for fractured rock masses," Journal of Rock Mechanics and Geotechnical Engineering, 2021.

[18] Y. Weng, S. Ruan, M. Li et al., "Feasibility study on sustainable magnesium potassium phosphate cement paste for 3D printing," Construction and Building Materials, vol. 221, pp. 595-603, Oct. 2019.

[19] C. Ma, Y. Liu, H. Zhou et al., "Influencing mechanism of sodium tripolyphosphate on the rheological properties of magnesium phosphate cement," Powder Technology, vol. 387, pp. 406-414, 2021.

[20] H. Li, H. Zhang, L. Li et al., "Utilization of low-quality desulfurized ash from semi-dry flue gas desulfurization by mixing with hemihydrate gypsum," Fuel, vol. 255, p. 115783, 2019.

[21] H. E. Abdelli, L. Mokrani, S. Kennouche, and J. B. de Aguiar, "Utilization of waste glass in the improvement of concrete performance: a mini review," Waste Management \& Research: The Journal for a Sustainable Circular Economy, vol. 38, no. 11, pp. 1204-1213, 2020, Nov. 2020.

[22] M. R. Ahmad, B. Chen, M. A. Haque, and S. F. A. Shah, "Utilization of industrial and hazardous waste materials to formulate energy-efficient hygrothermal bio-composites," Journal of Cleaner Production, vol. 250, p. 119469, 2020 Mar. 2020.

[23] L. J. Gardner, S. A. Bernal, S. A. Walling, C. L. Corkhill, J. L. Provis, and N. C. Hyatt, "Characterisation of magnesium potassium phosphate cements blended with fly ash and ground granulated blast furnace slag," Cement and Concrete Research, vol. 74, pp. 78-87, 2015.

[24] B. Xu, B. Lothenbach, and $\mathrm{H}$. Ma, "Properties of fly ash blended magnesium potassium phosphate mortars: effect of the ratio between fly ash and magnesia," Cement and Concrete Composites, vol. 90, pp. 169-177, 2018.

[25] J. Yang, J. Lu, Q. Wu, M. F. Xia, and X. Li, "Influence of steel slag powders on the properties of MKPC paste," Construction and Building Materials, vol. 159, pp. 137-146, 2018.

[26] G. Mingzhong, H. Haichun, X. Shouning et al., "Discing behavior and mechanism of cores extracted from Songke-2 well at depths below 4,500 m," International Journal of Rock Mechanics and Mining Sciences, vol. 149, p. 104976, 2022.

[27] Y. Dai, Y. Tan, Y. Wang, Q. Yang, and C. Lu, "Properties of cement-based bolt-grouting materials modified with alunite and gypsum," Advances in Cement Research, vol. 28, no. 6, pp. 403-408, 2016.

[28] A. S. Wagh, Chemically Bonded Phosphate Ceramics: TwentyFirst century Materials with Diverse Applications, Elsevier, 2016.

[29] Y. Tan, H. Yu, Y. Li, W. Bi, and X. Yao, "The effect of slag on the properties of magnesium potassium phosphate cement," Construction and Building Materials, vol. 126, pp. 313-320, 2016, Nov. 
[30] Y. Liu and B. Chen, "Research on the preparation and properties of a novel grouting material based on magnesium phosphate cement," Construction and Building Materials, vol. 214, pp. 516-526, 2019.

[31] L. Wang, I. K. M. Yu, D. C. W. Tsang et al., “Transforming wood waste into water-resistant magnesia-phosphate cement particleboard modified by alumina and red mud," Journal of Cleaner Production, vol. 168, pp. 452-462, 2017.

[32] Z. Li, J. Zhang, S. Li, Y. Gao, C. Liu, and Y. Qi, "Effect of different gypsums on the workability and mechanical properties of red mud-slag based grouting materials," Journal of Cleaner Production, vol. 245, p. 118759, 2020 Feb.

[33] Z. Dou, Y. Liu, X. Zhang et al., "Influence of layer transition zone on rainfall-induced instability of multilayered slope," Lithosphere, vol. 2021, no. Special 4, p. 2277284, Lithosphere, 2021.

[34] C. K. Chau, F. Qiao, and Z. Li, "Microstructure of magnesium potassium phosphate cement," Construction and Building Materials, vol. 25, no. 6, pp. 2911-2917, 2011, Jun. 2011.

[35] Y. Jiang, M. R. Ahmad, and B. Chen, "Properties of magnesium phosphate cement containing steel slag powder," Construction and Building Materials, vol. 195, pp. 140-147, 2019, Jan. 2019.

[36] Y. Liu, Z. Qin, and B. Chen, "Influence of low-grade bauxite on the properties of magnesium phosphate cement," Construction and Building Materials, vol. 242, p. 118052, 2020.

[37] Y. Liu, Z. Qin, and B. Chen, "Experimental research on magnesium phosphate cements modified by red mud," Construction and Building Materials, vol. 231, p. 117131, 2020 Jan. 2020.

[38] J.-Q. Liu, K.-V. Yuen, W.-Z. Chen, X.-S. Zhou, and WeiWang, "Grouting for water and mud inrush control in weathered granite tunnel: a case study," Engineering Geology, vol. 279, p. 105896, 2020.

[39] Z. Jiang, C. Qian, and Q. Chen, "Experimental investigation on the volume stability of magnesium phosphate cement with different types of mineral admixtures," Construction and Building Materials, vol. 157, pp. 10-17, 2017.

[40] C. Ma and B. Chen, "Properties of magnesium phosphate cement containing redispersible polymer powder," Construction and Building Materials, vol. 113, pp. 255-263, 2016.

[41] Z. Qin, C. Ma, Z. Zheng, G. Long, and B. Chen, "Effects of metakaolin on properties and microstructure of magnesium phosphate cement," Construction and Building Materials, vol. 234, p. 117353, 2020 UNSP 117353Feb. 2020.

[42] X. Yang, J. Liu, H. Li, and Q. Ren, "Performance and ITZ of pervious concrete modified by vinyl acetate and ethylene copolymer dispersible powder," Construction and Building Materials, vol. 235, p. 117532, 2020 UNSP 117532Feb. 2020.

[43] Z. Qin, S. Zhou, C. Ma, G. Long, Y. Xie, and B. Chen, "Roles of metakaolin in magnesium phosphate cement: effect of the replacement ratio of magnesia by metakaolin with different particle sizes," Construction and Building Materials, vol. 227, p. 116675, 2019.

[44] C. Zhu, Z. Yan, Y. Lin, F. Xiong, and Z. Tao, "Design and application of a monitoring system for a deep railway foundation pit project," Ieee Access, vol. 7, pp. 107591-107601, 2019.

[45] C. Shi, J. Yang, N. Yang, and Y. Chang, "Effect of waterglass on water stability of potassium magnesium phosphate cement paste," Cement and Concrete Composites, vol. 53, pp. 83-87, 2014.

[46] C. Ma, Y. Liu, H. Zhou, Z. Jiang, W. Ren, and F. He, "Influencing mechanism of mineral admixtures on rheological properties of fresh magnesium phosphate cement," Construction and Building Materials, vol. 288, p. 123130, 2021 Jun. 2021.

[47] Y. Shi, B. Chen, and M. R. Ahmad, "Effects of alumina as an effective constituent of metakaolin on properties of magnesium phosphate cements," Journal of Materials in Civil Engineering, vol. 31, no. 8, p. 04019147, 2019.

[48] N. Liu and B. Chen, "Experimental research on magnesium phosphate cements containing alumina," Construction and Building Materials, vol. 121, pp. 354-360, 2016.

[49] C. You, J. Qian, J. Qin, H. Wang, Q. Wang, and Z. Ye, “Effect of early hydration temperature on hydration product and strength development of magnesium phosphate cement (MPC)," Cement and Concrete Research, vol. 78, pp. 179-189, 2015.

[50] G. Hanqing, Y. Xiaoguang, Z. Chaoming, Y. Dadi, Z. Qi, and L. Zhongfei, "Application study of steel slag powder in cement based grouting material," Concrete, no. 2, pp. 85-87, 2014.

[51] E. Adesanya, K. Ohenoja, A. Di Maria, P. Kinnunen, and M. Illikainen, "Alternative alkali-activator from steel-making waste for one-part alkali-activated slag," Journal of Cleaner Production, vol. 274, p. 123020, 2020 Nov.

[52] J. Wang, J. Xie, Y. Wang, Y. Liu, and Y. Ding, "Rheological properties, compressive strength, hydration products and microstructure of seawater-mixed cement pastes," Cement and Concrete Composites, vol. 114, p. 103770, 2020.

[53] H. Ma and Y. Li, "Discussion of the paper "Characterisation of magnesium potassium phosphate cement blended with fly ash and ground granulated blast furnace slag" by L.J. Gardner et al," Cement and Concrete Research, vol. 103, pp. 245-248, 2018.

[54] J. Zhang, S. Li, Z. Li, C. Liu, Y. Gao, and Y. Qi, "Properties of red mud blended with magnesium phosphate cement paste: feasibility of grouting material preparation," Construction and Building Materials, vol. 260, p. 119704, 2020 Nov. 2020. 